\title{
Noise levels of a track-laying tractor during field operations in the vineyard
}

\author{
Pietro Catania, Mariangela Vallone \\ University of Palermo. Dipartimento di Scienze Agrarie e Forestali, Palermo, Italy
}

\begin{abstract}
Noise in agriculture is one of the risk factors to be taken into account in the assessment of the health and safety of workers; in particular, it is known that the tractor is a source of high noise. The Italian Low Decree 81/2008 defined the requirements for assessing and managing noise risk identifying a number of procedures to be adopted at different noise levels to limit workers exposure. This paper concerns the analysis of the noise risk arising from the use of a tracklaying tractor during field operations carried out in the vineyard. The objective of this study was to evaluate the noise level that comes close to the ear of the operator driving the tractor measuring the values of equivalent sound level (Leq(A)) and peak sound pressure (LCpk). We considered four options related to the same tractor coupled with the following tools to perform some farming operations: rototilling, chisel plough, flail mowers and vibro farmer. We considered three test conditions: T1 in flat (slope 0\%), T2 uphill and T3 downhill (both 30\% slope). The instrument used for the measurements is a precision integrating portable sound level meter, class 1, model HD2110L by Delta OHM, Italy. Each survey lasted 2 minutes, with an interval of measurement equal to $0.5 \mathrm{~s}$. The tests were performed in compliance with the standards ISO 9612 and ISO 9432. The results show that the measured sound levels exceed the limits allowed by the regulations in almost all the test conditions; values exceeding the threshold limit of $80 \mathrm{~dB}(\mathrm{~A})$ were recorded coming up to a maximum value of $92.8 \mathrm{~dB}(\mathrm{~A})$ for flail mowers in test T1. When limits imposed by the regulations are exceed-
\end{abstract}

Correspondence: Mariangela Vallone, University of Palermo. Dipartimento di Scienze Agrarie e Forestali Viale Delle Scienze Edificio 4, 90128 Palermo, Italy.

Tel. +39.91 .23865609 .

E-mail: mariangela.vallone@unipa.it

Key words: noise risk, tractor, vineyard.

Contributions: the authors contributed equally.

Conflict of interests: the authors declare no potential conflict of interests.

Conference presentation: part of this paper was presented at the $10^{\text {th }}$ Italian Conference AIIA (Associazione Italiana di Ingegneria Agraria), 2013 September 8-12, Viterbo, Italy.

CCopyright P. Catania and M. Vallone, 2013

Licensee PAGEPress, Italy

Journal of Agricultural Engineering 2013; XLIV(s2):e154

doi:10.4081/jae.2013.s2.e154

This article is distributed under the terms of the Creative Commons Attribution Noncommercial License (by-nc 3.0) which permits any noncommercial use, distribution, and reproduction in any medium, provided the original author(s) and source are credited. ed, the operator is obliged to wear the appropriate Personal Protective Equipment.

\section{Introduction}

Noise in agriculture is one of the risk factors to be taken into account for the evaluation of health and safety of workers. In particular, one of the major sources of discomfort for the workers operating a tractor is the noise to which they are subjected during work (Karamounsantas et al., 2009).

In Italy, Law Decree 81/2008 has defined the obligations of noise assessment and risk management, identifying a series of procedures to be adopted at the different noise levels in order to limit the exposure of workers. Excessive noise, in fact, is a global occupational health hazard with considerable social and physiological impacts, including noise-induced hearing loss (NIHL) (Deborah et al., 2005).

Directive 2003/10/EC of the European Parliament was enacted on the minimum health and safety requirements regarding the exposure of workers to the risks arising from physical agents (noise).

It stipulates an upper average limit of noise exposure of a worker during an eight hours shift of work at $85 \mathrm{~dB}(\mathrm{~A})$. This level is supposed to inhibit hearing impairments of workers (Moselhi et al., 1979). Even the ILO (International Labour Organization) indication agree with this.

Many authors carried out researches on noise risk in agriculture, in particular in the wood processing industry (Zimbalatti et al., 2010), oil mill (Porceddu and Dionigi, 2010), pasta factory (Bianchi et al., 2008), in mechanical harvest of hazelnuts (Cecchini et al., 2010) and on tractors in field conditions with various implements (Dewangan et al., 2005).

This paper concerns the analysis of the noise risk arising from the use of a track-laying tractor during field operations carried out in the vineyard; the aim is to evaluate noise at ear level of operators driving a track-laying tractor measuring the equivalent sound level (Leq(A)) and peak sound pressure (LCpk).

\section{Materials and methods}

\section{Machines used in the tests}

The tractor used during the tests is the track-laying tractor Trekker $80 \mathrm{~F}$ by Landini (Figure 1), without cab, equipped with an anti-tip device, $58 \mathrm{~kW}$ power, Perkins engine 1104D-44 (Table 1).

Four test conditions were realized coupling the same tractor with the following tools to perform some farming operations in vineyard (Figure 2): rototilling, chisel plough, flail mowers and vibro farmer: rototilling (RT)

chisel plough (CP)

flail mowers (FM)

vibro farmer (VF).

The tests were carried out in a vineyard situated in the countryside 
of Santa Margherita Belice (province of Agrigento, Sicily). Two homogeneous plots of vineyard, about $200 \mathrm{~m}$ long, were identified different only for slope: $0 \%$ and $30 \%$. The tests were performed during the execution of the cultivation operations in the following conditions:

flat, test named T1;

uphill, test named T2;

downhill, test named T3.

The average forward speed of the tractor was $2.5 \mathrm{~km} / \mathrm{h}$ in test T2 and $3.0 \mathrm{~km} / \mathrm{h}$ in tests T1 and T3.

\section{Instruments used during the tests}

The instrument used in the tests is a precision integrating portable sound level meter by Delta OHM, Italy, model HD2110L.

Table 1. Main technical characteristics of the track-laying tractor used in the tests.

\begin{tabular}{lccccc}
$\begin{array}{l}\text { Mass } \\
{[\mathrm{kg}]}\end{array}$ & $\begin{array}{c}\text { Wheel } \\
\text { track } \\
{[\mathrm{mm}]}\end{array}$ & $\begin{array}{c}\text { Wheelbase } \\
{[\mathrm{mm}]}\end{array}$ & $\begin{array}{c}\text { Seat } \\
\text { b1 b2 h } \\
{[\mathrm{cm}]}\end{array}$ & Year & $\begin{array}{c}\text { Hours of } \\
\text { work } \\
{[\mathrm{n}]}\end{array}$ \\
\hline 3800 & 1100 & 1650 & $40 \times 41 \times 39$ & 2005 & 4390 \\
\hline
\end{tabular}

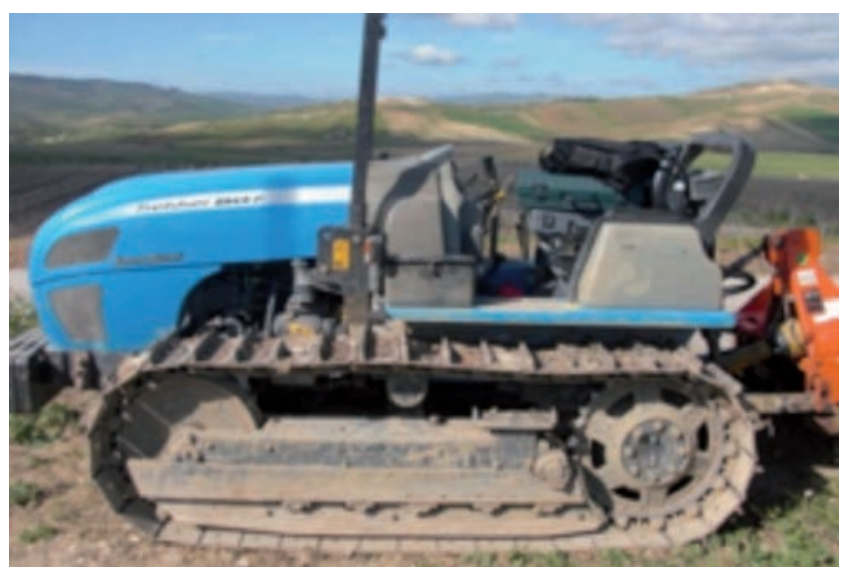

Figure 1. Track-laying tractor Trekker $80 \mathrm{~F}$ by Landini used in the tests.
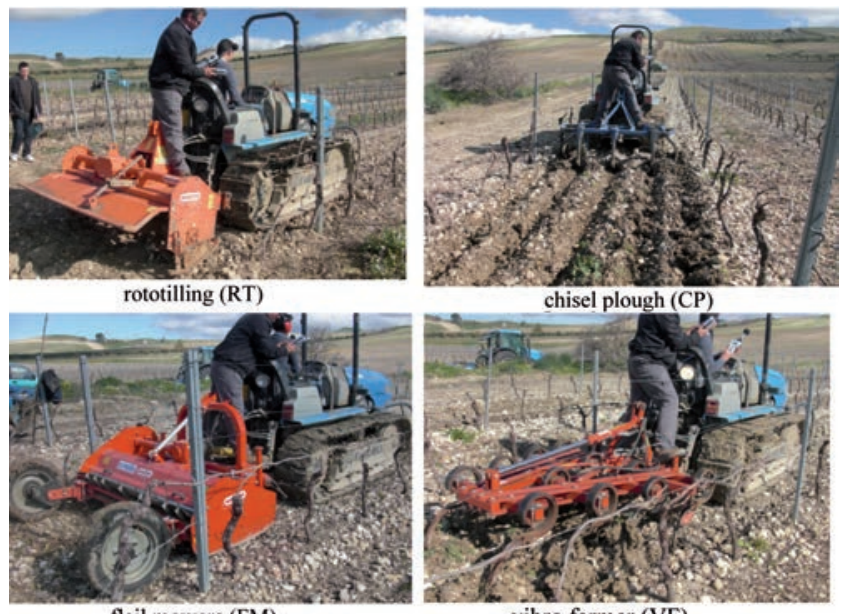

flail mowers (FM)

vibro farmer (VF)

Figure 2. Machines used during the tests.
The instrument complies with class 1 specifications of IEC 61672-1, IEC 60651 and IEC 60804 and is able to perform all the measurements required by Italian legislation on the protection of workers from the risk of noise exposure (Law Decree 81/2008 and UNI9432 standard). The constant percentage bandwidth filters are compliant with class 0 IEC 61260 specifications and the microphone with IEC 61094-4. The tests were carried out in compliance with ISO 9612 and ISO 9432 standards.

During the measurements the microphone was placed near the worker's ear at a distance of at least $0.1 \mathrm{~m}$ from the entrance of the external ear canal, approximately $0.04 \mathrm{~m}$ above the shoulder. Each measurement had a duration of 2 minutes (the case of stationary noise source) and the parameters were analyzed at intervals of 0.5 seconds.

We measured A-weighted time-averaged sound pressure level (LAeq) and C-weighted peak sound pressure level (LCpk). In addition, a $\mathrm{C}$-weighted ex post measurement in the point of greatest noise was realized.

As required by article 189 of Law Decree 81/2008, the worker does not have to be exposed to $\mathrm{L}_{\mathrm{Eex}, 8 \mathrm{~h}}$ values (occupational noise) reported to 8 working hours higher than $80 \mathrm{~dB}(\mathrm{~A})$ and to LCpk exceeding 135 $\mathrm{dB}(\mathrm{C})$.

$\mathrm{L}_{\text {Eex }, 8 \mathrm{~h}}$ values is given by the following equation:

$$
\mathrm{L}_{\mathrm{EX}, 8 \mathrm{~h}}=\mathrm{L}_{\mathrm{Aeq}, \mathrm{Te}}+10 \log \left(\mathrm{T}_{\mathrm{e}} / \mathrm{T}_{0}\right)
$$

where $\mathrm{T}_{\mathrm{e}}$ is the effective duration, in hours, of the working day and $\mathrm{T}_{0}$ is the reference duration equal to 8 hours. In this case $\mathrm{T}_{\mathrm{e}}$ was assumed to be 4.5 hours.

Before each series of measurements the instrument calibration was performed applying a sound calibrator. The collected data were downloaded to the PC for further processing.

Tests were carried out in triplicates. Analysis of variance and Tukey's test were performed using Statgraphics Centurion by Statpoint inc., USA.

\section{Results and discussion}

A-weighted time-averaged sound pressure levels (LAeq) in test T1 are shown in Figure 3 for the 4 operating machines.

Noise pressure values obtained in T1 show a minimum of $86.5 \mathrm{~dB}(\mathrm{~A})$ obtained by the chisel plough and a maximum of $92.8 \mathrm{~dB}(\mathrm{~A})$ by the flail mowers. Figure 3 shows that the exposure limit value established by the article 189 of Law Decree $81 / 2008$ (equal to $87 \mathrm{~dB}(\mathrm{~A})$ ) is exceeded

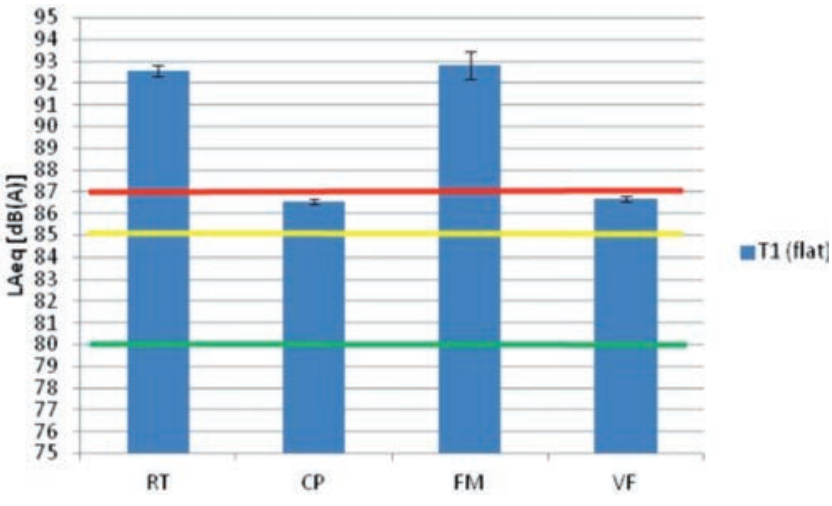

Figure 3. Noise pressure level in test T1 (flat) for rototilling (RT), chisel plough (CP), flail mowers (FM) and vibro farmer (VF) treatments (data are reported as means \pm standard deviations of the three replicates). 
only by rototilling and flail mowers. Both the upper action value of 85 $\mathrm{dB}(\mathrm{A})$ and the lower action value (equal to $80 \mathrm{~dB}(\mathrm{~A})$ ) are exceeded by all the machines. Statistical analysis $(\mathrm{p}<0.05)$ shows significant differences between all the machines except chisel plough - vibro farmer and rototilling - flail mowers.

Figure 4 shows the A-weighted time-averaged sound pressure levels (LAeq) obtained by the four machines in test T2.

Noise pressure values obtained in $\mathrm{T} 2$ show a minimum of $86.6 \mathrm{~dB}(\mathrm{~A})$ for chisel plough and a maximum of $92.2 \mathrm{~dB}(\mathrm{~A})$ for flail mowers. The exposure limit value is exceeded by all the machines except chisel plough. Both the upper action value of $85 \mathrm{~dB}(\mathrm{~A})$ and the lower action value (equal to $80 \mathrm{~dB}(\mathrm{~A})$ ) are exceeded by all the machines. Statistical analysis $(p<0.05)$ shows significant differences between all the machines.

Figure 5 shows the A-weighted time-averaged sound pressure levels (LAeq) in test T3.

Noise pressure values obtained in $\mathrm{T} 3$ show a minimum of $85.1 \mathrm{~dB}(\mathrm{~A})$ for chisel plough and a maximum of $91.5 \mathrm{~dB}(\mathrm{~A})$ for flail mowers. The exposure limit value is exceeded only by rototilling and vibro farmer. As obtained in T2, both the upper action value of $85 \mathrm{~dB}(\mathrm{~A})$ and the lower action value (equal to $80 \mathrm{~dB}(\mathrm{~A})$ ) are exceeded by all the machines.

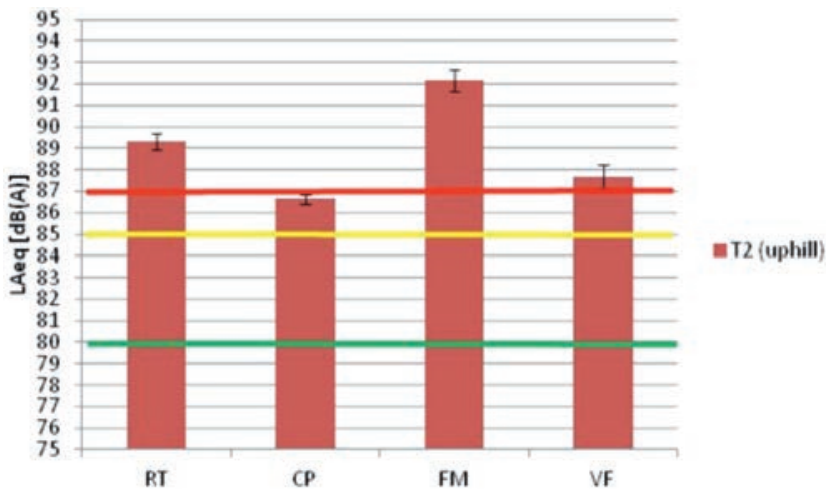

Figure 4. Noise pressure level in test T2 (uphill) for rototilling (RT), chisel plough (CP), flail mowers (FM) and vibro farmer (VF) treatments (data are reported as means \pm standard deviations of the three replicates).
Statistical analysis $(\mathrm{p}<0.05)$ shows significant differences between all the machines.

C-weighted peak sound pressure leves (LCpk) obtained in the different tests are shown in Figure 6.

Neither the exposure limit value equal to $140 \mathrm{~dB}(\mathrm{C})$ according to the cited art. 189 of Law Decree 81/2008, or the upper and lower action values (equal to $137 \mathrm{~dB}(\mathrm{C})$ and $135 \mathrm{~dB}(\mathrm{C})$ ) are reached or exceeded by any of the tested machines.

Finally, we determined the $\mathrm{L}_{\mathrm{Ex}, 8 \mathrm{~h}}$ values considering a daily duration of the operator personal exposure of 4.5 hours. The results are summarized in Table 2.

\section{Conclusions}

The results of the experiments carried out allow us to affirm that: the highest noise pressure values were obtained by the flail mowers. This occurs in the three test conditions;

the other machine that gave high noise levels was rototilling in the three test conditions;

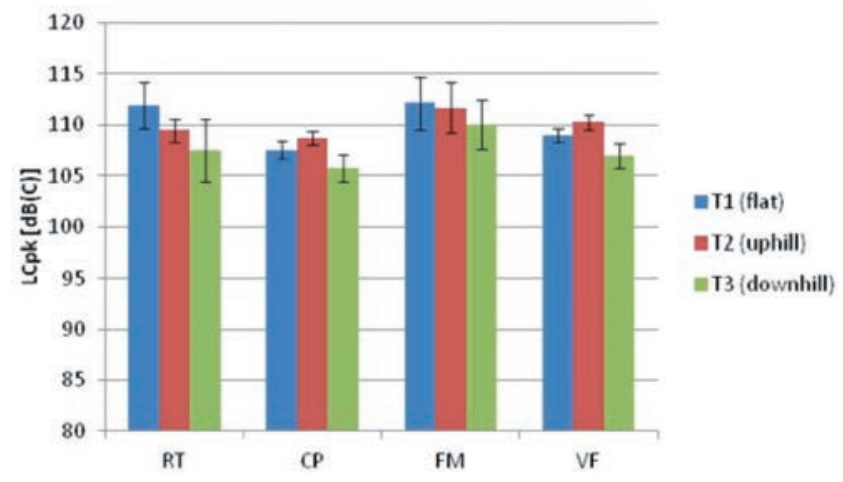

Figure 6. C-weighted peak sound pressure level LCpk in the three tests for rototilling $(\mathrm{RT})$, chisel plough $(\mathrm{CP})$, flail mowers (FM) and vibro farmer (VF) treatments (data are reported as means \pm standard deviations of the three replicates).

Table 2. Daily noise exposure level $\mathbf{L}_{\mathrm{Ex}, 8 \mathrm{sh}}$.

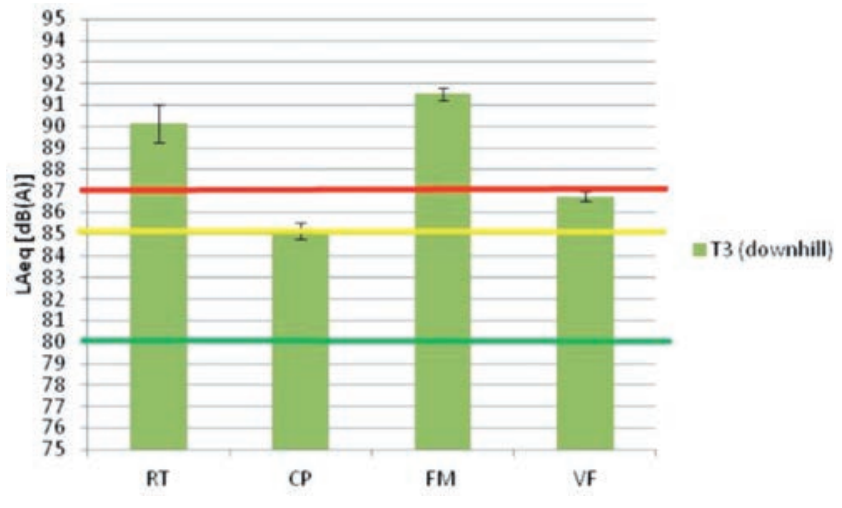

Figure 5. Noise pressure level in test T3 (downhill) for rototilling (RT), chisel plough (CP), flail mowers (FM) and vibro farmer (VF) treatments (data are reported as means \pm standard deviations of the three replicates).

\begin{tabular}{lll} 
& & $L_{\mathrm{Ex}, 8 \mathrm{n}}[\mathrm{dB}(\mathrm{C})]$ \\
$\mathrm{T} 1$ & $\mathrm{RT}$ & 90.07 \\
& $\mathrm{CP}$ & 84.04 \\
& $\mathrm{FM}$ & 90.30 \\
$\mathrm{~T} 2$ & 84.20 \\
& VF & 86.80 \\
& RT & 84.12 \\
& CP & 89.66 \\
& FM & 85.19 \\
\hline T3 & VF & 87.65 \\
& RT & 82.64 \\
& CP & 89.01 \\
& FM & 84.25 \\
\hline
\end{tabular}


noise pressure values measured during the three tests are always higher than the lower and the higher action values identified by law, respectively equal to $80 \mathrm{~dB}(\mathrm{~A})$ and $85 \mathrm{~dB}(\mathrm{~A})$;

the exposure limit value of $87 \mathrm{~dB}(\mathrm{~A})$ is reached in $\mathrm{T} 1$ only by rototilling and flail mowers, in T2 by rototilling, flail mowers and vibro farmer and in $\mathrm{T} 3$ by rototilling and flail mowers again;

with reference to the peak values, neither the exposure limit value equal to $140 \mathrm{~dB}(\mathrm{C})$, or the upper and lower action values (equal to 137 $\mathrm{dB}(\mathrm{C})$ and $135 \mathrm{~dB}(\mathrm{C})$ ) are reached or exceeded by any of the tested machines in the three tests;

daily noise exposure levels LEx,8h obtained by rototilling and flail mowers overcome the exposure limit value of $87 \mathrm{~dB}(\mathrm{~A})$;

the use of appropriate PPE is required when limits imposed by the regulations are exceeded.

\section{References}

Bianchi B., Cassano F., Mongelli C. Experimental trials to evaluate risks from noise and particulate matter in a pasta factory. International Conference: "Innovation Technology to Empower Safety, Health and Welfare in Agriculture and Agro-food Systems", 2008, Ragusa, Italy, September 15-17.

Cecchini M., Monarca D., Guerrieri M., Lingero E., Bessone W., Bedini R., Menghini G. Noise Levels for Modern Hazelnut Harvesters. Proceedings of the International Conference "Work Safety and Risk Prevention in Agro-food and Forest Systems". September 1618, 2010 Ragusa, Italy.
Deborah, I. N., Robert, Y. N., Marison, C. B., \& Marilyn, F. The global burden of occupational noise induced hearing loss. American Journal of Industrial Medicine, 2005, 48(6), 446-458.

Dewangan K.N., Prasanna Kumar G.V., Tewari V.K. Noise characteristics of tractors and health effect on farmers, Applied Acoustics, 2005, 66, 1049-1062.

European Parliament and Council, Directive 2003/10/EC of the European Parliament and of the Council of 6 February 2003 on the minimum health and safety requirements regarding the exposure of workers to the risks arising from physical agents (noise).

International Labour Organization (ILO). Health, Safety and Environment: A Series of Trade Union Education Manuals for Agricultural Workers, 2004, ISBN:92-2-115 192-1.

Karamounsantas D., Varzakas T., Kanakis A., Dalamagas B.C., Noise levels produced by agricultural machinery and different farming processes. International Journal of Acoustics and Vibration, 2009, 14(4), 220-225.

Law Decree 81, 9 April 2008 of the Italian Republic.

Moselhi M., El-Sadik, Y. M. and El-Dakhakhny, A., A six year follow up study for evaluation of the $85 \mathrm{dBA}$ safe criterion for noise exposure. Am. Ind. Hyg. Assoc. J., 1979, 40(5), 424-426.

Porceddu P.R., Dionigi M. Evaluation of Noise Levels in Olive Mills. Proceedings of the International Conference "Work Safety and Risk Prevention in Agro-food and Forest Systems". September 1618, 2010 Ragusa, Italy.

Zimbalatti G., Proto A.R., Negri M. Acoustic Levels in the Wood Processing Industry in Northeast Italy. Proceedings of the International Conference "Work Safety and Risk Prevention in Agro-food and Forest Systems". September 16-18, 2010 Ragusa, Italy. 